\title{
Nortriptyline plus interpersonal psychotherapy was effective in major depression in older adults
}

\author{
Reynolds CF 3rd, Frank E, Perel JM, et al. Nortriptyline and interpersonal psychotherapy as maintenance therapies for recurrent \\ major depression. A randomized controlled trial in patients older than 59 years. JAMA 1999 Jan 6;281:39-45.
}

\section{Question}

In older patients with major depression, how effective are nortriptyline hydrochloride and interpersonal psychotherapy (IPT) in preventing recurrence of depressive episodes?

\section{Design}

Randomised controlled trial with 3 years of maintenance treatment.

\section{Setting}

Geropsychiatric research clinic in Pittsburgh, Pennsylvania, USA.

\section{Patients}

180 patients who were $\geqslant 60$ years of age (mean age 68 y, $75 \%$ women) and met criteria for recurrent non-psychotic unipolar major depression according to the Schedule for Affective Disorders and Schizophrenia-Lifetime version. Other inclusion criteria were at least in their second lifetime episode, interepisode wellness interval of $\leqslant 3$ years, Hamilton Depression Rating Scale score $\geqslant 17$, and Folstein Mini-Mental State Examination score $\geqslant 27$. Of 107 patients who successfully completed acute treatment, continuation therapy, and began maintenance therapy (124 randomised), 96 patients (90\%) completed the study.

\section{Intervention}

Patients were allocated to nortriptyline hydrochloride, 80-120 $n g / m l(n=24)$, placebo $(n=29)$, IPT $(n=21)$, or nortriptyline and IPT $(\mathrm{n}=22)$.

\section{Main outcome measures}

Recurrence of depressive episodes at 3 years.

\section{Main results}

Combined treatment with nortriptyline and IPT led to the lowest recurrence rate and was superior to placebo $(\mathrm{p}<0.001)$, to IPT alone $(p=0.003)$, and probably to nortriptyline alone $(\mathrm{p}=0.06) \quad$ (table). Lower recurrence rates occurred with nortriptyline alone compared with placebo $(\mathrm{p}<0.001)$ but not with IPT alone $(\mathrm{p}=0.16)$ (table). IPT was superior to placebo $(p=0.03)$ (table). Patients $\geqslant 70$ years of age had the greatest rate of recurrence in the first year; combined treatment was the most effective in preventing recurrence in this age group.

\section{Conclusion}

Nortriptyline and interpersonal psychotherapy prevented recurrences of major depressive episodes in older adults.

Depressive episode recurrence rates at 3 years for nortriptyline, interpersonal psychotherapy (IPT), and placebo*

\begin{tabular}{llll}
\hline Comparison & Event rates & $R R R(95 \%$ CI) & NNT (CI) \\
\hline $\begin{array}{l}\text { Nortriptyline and IPT } v \\
\quad \text { placebo }\end{array}$ & $20 \% v 90 \%$ & $78 \%(56$ to 90$)$ & 1 (1 to 2) \\
$\begin{array}{l}\text { Nortriptyline and IPT } v \text { IPT } \\
\text { Nortriptyline and IPT } v\end{array}$ & $20 \% v 64 \%$ & $67 \%(33$ to 87$)$ & 2 (2 to 6) \\
$\quad$ nortriptyline & $20 \% v 43 \%$ & $53 \%(-7.3$ to 81$)$ & Not significant \\
Nortriptyline $v$ placebo & $43 \% v 90 \%$ & $52 \%(29$ to 71$)$ & $2(2$ to 4$)$ \\
Nortriptyline $v$ IPT & $43 \% v 64 \%$ & $33 \%(-12$ to 61$)$ & Not significant \\
IPT $v$ placebo & $64 \% v 90 \%$ & $29 \%(4.6$ to 51$)$ & $4(2$ to 30$)$
\end{tabular}

*Abbreviations defined in glossary; RRR, NNT, and CI calculated from data in article.

Source of funding: National Institute of Mental Health.

For correspondence: Dr C F Reynolds 3rd, Department of Psychiatry, University of Pittsburgh Medical Center, 3811 O'Hara Street, Pittsburgh, PA 15213, USA. Fax +1 4126242841.

\section{Commentary}

Most studies looking at the outcome of depression in old age have reported similar results: $20-30 \%$ of patients recover completely and $70-80 \%$ relapse or remain depressed at follow up. The study by Reynolds et al shows that treatment with nortriptyline or IPT is superior to placebo in preventing relapse. It also suggests that the combination of these 2 treatments offers patients the best possible 3 year outcome.

Common sense suggests that psychotherapy should improve the outcome of patients by increasing compliance and addressing the psychosocial issues that are often associated with depression in old age. Cognitive behavioural and interpersonal therapies were designed to address clearly defined problems and may therefore be particularly suitable for use in older adults. Reynolds et al showed that long term IPT is associated with fewer relapses. It would be interesting to see if these results can be replicated with the use of larger samples of patients and if other forms of psychological treatment are also effective.

The most relevant clinical question arising from this study is whether the long term combined use of IPT and nortriptyline is the most effective strategy in the elderly. The answer to this question is uncertain for several reasons. Firstly, it is unclear if the positive effects of psychotherapy are dependent on its indefinite continuation. Secondly, the use of a more flexible drug regimen could have produced a more favourable outcome. A simple change of medication may effectively treat the relapse of depressive symptoms in the elderly. ${ }^{1}$ In addition, newer antidepressants produce less troublesome side effects than tricylics-their use may improve compliance to treatment and, as a consequence, reduce the risk of relapse. Thirdly, the sam- ple of patients selected for this study is unlikely to adequately represent the population of older people with depression. They all had a recurrent depressive disorder (median number of previous episodes $=4$ ) with $>1$ episode during the previous 3 years. Less severe forms of illness may not require combination of treatments to avoid relapse.

Reynolds et al remind us that the maintenance treatment of older adults with recurrent depression should not always be limited to the use of antidepressants. Future studies need to clarify which are the most cost effective options to avoid relapse of depressive symptoms in older adults.

Osvaldo P Almeida, MD, PhD University of Western Australia Perth, Australia

1 Flint AJ, Rifat SL. Br J Psychiatry 1997;170:268- 